\title{
AKULTURASI ESTETIK BUNGONG HIAS DALAM MASJID BAITURRAHMAN KOTA BANDA ACEH
}

\author{
Muhammad Zaki Al-Syafani \\ Pengkajian Seni Kriya Program Pascasarjana Institut Seni Indonesia Padangpanjang Jl. Bahder Johan, \\ Guguak Malintang, Padangpanjang, Kota Padangpanjang, 27126. Sumatera Barat. Indonesia. Email: \\ muhammadzaky04032012@gmail.com
}

\begin{abstract}
Abstrak
Penelitian pada akulturasi estetik bungong hias masjid Baiturrahman menggunakan metode kerangka teori sebagai pisau bedah analisis, teori akulturasi mengarah pada pemikiran Koentjaraningrat, teori estetika dan teori semiotika Charles Sanders Pierce memahami komunikasi pembuktian tanda-tanda dari sebuah kenyataan. Analisis bungong hias estetik terhadap persilangan budaya Eropa dan Timur Tengah, menelusuri dengan proses perjalanan akulturasi yang mempengaruhi masjid Baiturrahman bungong hias berdasarkan literatur komunikasi indikator ikon, indeks, dan symbol. Bentuk dan pemaknaan bungong hias berdasarkan semiotik dari hasil representasi flora, alam, kaligrafi dan arabesque. Bentuk unsur flora terdiri bungong meusingklet, bungong ban keumang, bungong meulu dan pucok rebong. Bentuk alam terdiri dari bintang bulen, rante, puta taloe, awan si oen, dan lampu kande. Bentuk kaligrafi dan arabesque terdiri dari unsur geometris dan lafad Allah dengan bentuk seni kaligrafi. Bungong hias tersebut memiliki makna filosofis sebagai kearifan lokal dari nilai-nilai budaya dalam mengatur kehidupan sosial masyarakat Aceh dan juga mempengaruhi acuan bentuk bungong hias baik dari segi arsitektur dan penererapan terhadap objek yang tersebar di Nusantara.
\end{abstract}

Kata Kunci: Akulturasi, Estetik, Bungong Hias

\begin{abstract}
Research on the aesthetic acculturation of the ornamental Bungong Baiturrahman mosque uses the theoretical framework method as an analytical scalpel; acculturation theory leads to Koentjaraningrat's thoughts, aesthetic theory, and Charles Sanders Pierce's semiotic theory understand communication evidence of signs from a reality. The analysis of the aesthetic ornamental bungong on the cross between European and Middle Eastern cultures traces the process of acculturation that affects the Baiturrahman bungong decorative mosque based on the communication literature of icon, index, and symbol indicators. The shape and meaning of ornamental bungong are based on a semiotic representation of flora, nature, calligraphy and arabesque. The elements of flora consist of Bungong Meusingklet, Bungong Ban Keumang, Bungong Meulu and Pucok Rebong. The natural form consists of a bulen star, rante, puta taloe, si oen, cloud, and kande lamp. Calligraphy and arabesque forms consist of geometric elements and the pronunciation of Allah with the art form of calligraphy. The ornamental bungong has a philosophical meaning as local wisdom of cultural values in regulating the social life of the Acehnese people and also influences the reference to the shape of the ornamental bungong both in terms of architecture and the application of objects scattered throughout the archipelago.
\end{abstract}

Keywords: Acculturation; Aesthetics; Ornamental Bungong 


\section{PENDAHULUAN}

Masjid di Indonesia cukup beragam bentuknya sesuai dengan ciri khas kebudayaan masyarakat daerahnya, begitu juga dengan Masjid Raya di Provinsi Aceh. Masjid ini terdapat di pusat Kota Banda Aceh, bernama Baiturrahman yang didirikan tahun 1612 M (abad ke-17) oleh Kesultanan Iskandar Muda. Kehadirannya menjadi simbol agama, budaya, semangat, kekuatan, perjuangan, dan nasionalisme masyarakat Aceh. Masjid Baiturrahman menjadi perhatian khusus oleh masyarakat pribumi dan pendatang dari luar daerah yang menjadi ikon central di tengahtengah pusat jantung Kota Banda Aceh bagian dari Serambi Mekkah.

Keindahan masjid baiturrahman merupakan pecampuran gaya Mughal, Moor juga penambahan payung eletrik yang terlihat seperti masjid Nabawi. Arsitektur dan dekoratif masjid Baiturrahman tidak terlepas dari pengaruh Barat dan Timur Tengah yang di adopsi oleh ide temuan arsitek pada awal pembagunan di era kolonial.

Nurdin dalam Ismail selanjutnya juga menyatakan, bahwa pada tahun 1873 masjid Baiturrahman pernah mengalami kehancuran akibat perang antara rakyat Aceh dengan Belanda. Namun setelah konflik bersenjata usai pada tahun 1879 masjid Baiturrahman kembali di bangun oleh pihak Belanda bergaya Moor dengan satu kubah oleh arsitek De Bruins. Tahun 1936 bangunan masjid mengalami perluasan bangunan dengan tiga kubah (Nurdin, 2004: 7-8).

Berdasarkan pernyataan Nurdin di atas dapat dipahami, bahwa ada perbedaan arsitektur pembangunan kembali masjid Baiturrahman di masa kepemimpinan Jendral Van Der Haidjen dengan kesultanan Iskandar Muda. Bila di masa kesultanan arsitektur masjid bergaya masjid pada umumnya atau prototipe, maka di masa Van Der Haidjen arsitektur masjid bergaya Indische Empire Style (gaya kerajaan Hindia Belanda). Upaya merubah arsitektur masjid di masa kepemimpinan Van Der Haidjen merupakan salah satu upaya mengambil hati rakyat Aceh agar tidak lagi melakukan perlawanan terhadap Belanda. Meskipun konflik senjata antara rakyat Aceh berhenti, namun masjid tersebut tidak diterima masyarakyat Aceh. Kehadiran masjid Baiturrahman yang di bangun oleh Belanda merupakan mayoritas kaphe (kafir), maka dengan adanya persepsi masyarakat Aceh tidak menerima tempat ibadah di bangun kafir. Berkat pencerahan yang dilakukan oleh Imam masjid Teungku Kadhi Malikul Adil (penasihat Sultan di bidang keagamaan), masjid tersebut diterima oleh rakyat Aceh setelah pembanggunan ke dua selesai dengan arsitektur serupa.

Bentuk dan ornamentasi masjid Baiturrahman berangkat dari proses akulturasi pengaruh kebudayaan Eropa dan Timur Tengah secara konseptual Ducth Colonial (gaya colonial) oleh arsitek De Bruins dan juga tidak menghilangkan secara keseluruhan unsur-unsur desian ornamen kultur Aceh.

Penerapan akulturasi pada bungong hias memiliki muatan atau pengaruh unsur budaya Barat dan Timur Tengah. Hal tersebut terlihat pada mimbar, mihrab, plafon dalam masjid, Ventilasi, tiang dalam masjid, dan pintu masuk masjid. Peneliti selanjutnya juga menemukan, bahwa estetik terhadap bungong hias masjid Baiturrahaman 
menjadi acuan bagi masyarakat ketika mendirikan masjid atau meunasah (surau) di daerahnya masing-masing.

Bungong hias merupakan pengabungan satuan pola yang disusun rapi dengan berulang-ulang, pola-pola tersebut dibentuk secara simetris. Terkait bungoeng hias (ornamen) pada masjid Baiturrahman, pola-pola terbentuk dari elemen flora, yakni motip seulanga, motip ajoe-ajoe, awan si oen, awan meucanek, bungong meulu, bungong meusingklet, pucok reboeng, dan bungong mawoe. Selanjutnya motif geometris pada bungong hias adalah segi lapan, segi enam. Motif aksara, yakni kaligrafi adapun berangkat dari alam bungong hias puta taloe, rante dan taloe ie

Berdasarkan bungoeng hias pada masjid Baiturrahman, terlihat pengaruh akulturasi estetik Barat dan Timur cukup kental di setiap bidang penempatan; yakni 1) geometris awan si oen pada plafon, Awan meucanek pada tiang dalam masjid, lampion gantung dan motif geometris pada atap berkaca dengan gaya Eropa. 2) pintu masuk masjid yang terbuat dari tembaga kuningan, bungoeng ajoe-ajoe pada tiang luar dengan bentuk gapura dengan tiga pintu senyawa, motif awan si oen pada bagian ventilasi sisi kiri dan kanan masjid, pucoek reboeng pada pergelangan kaki tiang dalam dan luar masjid. 3) Geometris segi lapan pada dinding depan masjid, mihrab masjid ruang utama setengah lingkaran di selimuti ornamen kaligrafi menyerupai Ka'bah bermaterial kuningan, motif bungoeng meulu, dan motif rante bergaya Arab pada di dinding dalam depan masjid Baiturrahman.

Perbedaan tersebut terlihat jelas dari segi unsur bangunan, yang terdiri dari beberapa elemen, yakni pintu utama masjid yang terbuat dari tembaga kuningan, plafon kaca dalam, ventilasi udara (Hindia Belanda), mimbar, kubah atap (Mughal), kolom pilar (Cordoba), lampion gantung dalam masjid, mihrab (Arab) dan palfon atas (Aceh) (wawancara, Amir Hamzah, Banda Aceh,13 Oktober 2019). Elemen-elemen tersebut menjadi daya tarik untuk diteliti karena elemen elemen pada bungoeng hias dipengaruhi estetik Barat dan Timur Tengah.

Bungong hias yang terdapat pada Penelitian bungoeng hias pada masjid Baiturrahman penting dilakukan agar hasil penelitian ini dapat memberi pencerahan kepada masyarakat Aceh tentang toleransi, seperti terlihat jelas pada masjid Baiturrahman dengan adanya pencampuran budaya luar yang tidak memandang perbedaan antara ras dan agama. Pengamatan bungoeng hias dari sisi akulturasi yang menjadi kajian analisis dalam masjid inilah yang menjadi daya tarik bagi penulis untuk mengetahui nilai dan simbol bungong hias dalam masjid Baiturrahman yang sudah menjadi bagunan ikon central bagi masyrakatAceh, maka penelitian ini akan di fokuskan kajian semiotika estetik. Penelitian dengan sudut pandang semiotik yang mengkaji tentang keterikatan antara ikon, indeks dan simbol terhadap sosial dengan kehadiran perpaduan pencampuran budaya Ducth Colonial bungong hias menjadi tolak ukur ragam hias di Nusantara.

Tinjauan pustaka dilakukan untuk memperoleh berbagai sumber penelitian yang dapat dijadikan landasan teori. Tinjauan ini dilakukan terhadap skripsi, tesis dan desertasi yang terkait dengan objek material masjid raya Baiturrahman di Kota Banda Aceh. Berbagai tulisan yang 
telah dihimpun baik berupa buku maupun artikel, ternyata kajian yang berhubungan langsung dengan objek formal "Akulturasi Estetik Bungong Hias Dalam Masjid Baiturrahman" belum pernah diteliti oleh para penelitian sebelumnya. Akan tetapi ada beberapa penelitian masjid Baiturrahman yang bersinggungan dengan bidang sejarah, kontruksi, dan juga mengenai ragam hias masjid Baiturrahman yang membahas secara jenis ornamentasi. Berdasarkan itu dapat dilakukan konsep dalam bentuk bagan sebagai teori dan Pisau bedah yang digunakan terhadap penelitaian ini menggunakan teori akulturasi dan semiotika Charles Sanders Pierce sebagai kerangka teoritis akulturasi bungong hias estetik dalam masjid Baiturrhaman Kota Banda Aceh. Adapun pendekatan teori pendukung menggunakan pendekatan sejarah estetika, Oliver Leaman (estetika Islam), Dharsono Sony Kartika, dan Jakob Sumardjo (filsafat seni).

Pembedahan akulturasi estetik menggunakan Koentjaraningrat agar mampu menganalisis dalam kehadiran bungong hias dari percampuran Barat, dan Timur Tengah hadir dalam Masjid Baiturrahaman. Akulturasi bahwa konsep proses sosial bahwa kelompok manusia dengan unsur kebudayaan tertentu dan dan menerima kebudayaan asing tanpa disadari dioalah ke dalam kebudayaan sendiri tanpa menyebabkan hilagnya kpribadian kebudayaan itu sendiri (Koentjaraningrat, 2009: 202). Akulturasi sudah hadir mulai abad 15 terahadap bagsa Eropa atas kekutan jajahan mereka yang mampu mempengaruhi nilai budaya, Agama, teknologi, arsitektur dan seni rupa. Akuturasi estetik pada bungong hias masjid Baiturrahman teradapat pada bangunan Serambi pertama dengan konsep ducth colonial.

Plato dalam Dharsono Sony Kartika memahami keindahan dalam tiga aspek yakni seperti pernyataan berikut:

"Tentang keindahan dalam arti yang luas, merupakan pengertian semula dari bangsa Yunani, yang di dalamnya tercakup pula ide kabaikan. Tentang watak yang indah dan hukum yang indah, sedangkan Aristoteles merumuskan keindahan sebagai sesuatu yang selain baik juga menyenangkan. Pengertian keindahan yang seluas-luasnya meliputi: keindahan seni, keindahan alam, dan keindahan intelektual. Pembagian dan pembedaan terhadap keindahan masih belum jelas apakah sesunghnya keindahan itu" (2017: 9-10).

Pada hakikatnya semua benda yang dianggap indah dan kemudian menyamakan kualitas pengertian keindahan. Jadi keindahan pada dasarnya adalah memiliki kualitas pokok tertentu yang terdapat pada sesuatu hal yang mengadung elemen mendasar. Diperkuat Monroe Beardsley dalam Dharsono Sony Kartika (2007: 76) menjelaskan, tiga ciri yang menjadi sifat indah pada benda estetis. Ketiga ciri yang dimaksud adalah: (1) kesatuan atau unity, (2) kerumitan atau complexity, (3) kesungguhan atau intensity.

\section{METODE PENELITIAN}

Pendekatan suatu penulisan karya ilmiah atau tugas akhir dalam capaian itu menggunakan dua pendekatan yaitu: kualitatif dan kuantitatif. Pendekatan kualitatif informan sebagai sumber data yang diperoleh, sedangkan kuantitatif responden sebgai sumber data dan informasi. Metode yang digunakan pada penelitian ini adalah metode kualitatif yang mendeskripsikan bungong hias pada 
masjid Baiturrahman Kota Banda Aceh (NAD) (Hamid Pitilima, 2011: 3).

Menurut Norman K. Denzim (dalam Hamid Pitilima, 2011: 1-3) mengatakan bahwa, "penelitianan kualitatif merupakan fokus perhatian dengan beragam metode, yang mencakup pendekatan interpretatif dan naturalistik terhadap objek kajian-kajiannya”. Artinya penelitian kulitattif mempelajari benda (objek) secara alamiah, yang berupaya untuk memahami dalam menafisirkan fenomena yang di lihat dari sisi makna yang dikaji berbagai data empiris study khusus, pengalaman pribadi, hasil pengalaman, intropeksi, interaksional dan visual.

Pengumpulan data merupakan salah satu yang harus dilakukan oleh para peneliti untuk melengkapi dan menjawab rumusan masalah yang sudah ada. Adapun sumber data dalam penelitian ini berbentuk, 1)observasi, 2) wawancara, 3)dokumentasidan dilanjutkan dengan 4)analisis data.

\section{HASIL DAN PEMBAHASAN}

Periodisasi kejayaan Islam di Aceh diperkirakan pada abad ke13 hingga masa kesultanan Iskandar Muda pada tahun 1636 (abad ke17). Namun ada pula pendapat Timur yang menyatakan abad ke $7 \mathrm{M}$ merupakan awal puncaknya islamisasi di kerjaan Aceh. Terdapat dua versi sejarah mengenai pembangunan masjid Baiturrahman, pertama didirikan pada tahun $1292 \mathrm{M}$ oleh Sultan Alauddin Johan Mahmudsyah. Kedua, masjid Baiturrahman didirikan oleh Sultan Iskandar Muda pada tahun $1612 \mathrm{M}$ (Ibrahim, 2003: 28-30). Berdasarkan pernyataan tersebut serta diperkuat oleh para ahli sejarah seperti Nurdin AR dan
Denys Lombard, dapat disimpulkan bahwa pembangunan masjid Baiturrahman didirikan pada zaman kesultanan Iskandar Muda pada tahun $1612 \mathrm{M}$.

Agresi Belanda dimulai pertama kali menyerang Aceh pada tanggal 19 Maret 1873 di siang hari, penyerangan dipimpin langsung oleh Jendral J.H.R. Kohler untuk berusaha merebut masjid Baiturrahman (Kremeer, 1920: 70). Agresi militer di dianggap gagal menaklukkan wilayah Aceh, bahkan menewaskan tentara Belanda 405 orang. Jendral Kohler tewas akibat terkena tembakan peluru pasukan Aceh, tepat di pohon glumpang. ${ }^{1}$ Akibat tewasnya Jendral Kohler, tentara Belanda terpaksa mundur dari wilayah Aceh dan kembali ke Batavia. (Ismail, 2004: 23).

J. Van Der Hadjen sebagai Gebernur militer menyadari bahwa kehancuran masjid Baiturrahman merupakan tindakan keliru, maka berinisiatif membangun kembali masjid Baiturrahman dengan tujuan meredamkan hati rakyat Aceh. Upaya ini dilakukan untuk mengguasai seluruh struktural pemerintahan di Aceh, hal ini dilakukan agar masyarakat Aceh tunduk ke Hindia Belanda. Tahun 1879 dilaksanakan peletakan batu pertama pembangunan Masjid Baiturrahman, arsitek yang dipercayakan adalah De Bruins, berbangsa campuran Itali-Belanda. Oleh karena itu, pembagunan masjid Baiturrahman dengan satu kubah berkonsep Ducth Colonial dan serta diserahkan ke masyarakat Aceh tahun 1881. Adapun kubah yang dibuat bergaya Moor dengan bentuk dan ciri-ciri masjid di Negara Islam, seperti percampuran Syro Egypto Style (bergaya Mesir Kuno), Hispano-Moresque Style

\footnotetext{
${ }^{1}$ Tempat tewasnya Jendral J.H.R. Kohler di pohon glumpang di depan Masjid Baiturrahman, yang sekarang dikenang nama pohon Kohler.
} 
MELAAYU ARTSAND JOURNAL

(gaya karakter Spanyol), Persian Style (gaya Persia), Ottoman Style (gaya Ottoman zaman Utsmaniyah), dan Indian Style (gaya Mughal).

Kremeer dalam Ismail, menyatakan proses pembagunan masjid Baiturrahman oleh pemerintah Belanda mengharapkan tenaga kerja yang dilibatkan masyarakat Aceh upaya menyelesaikan proyek pembangunan oleh Hindia Belanda. Namun persoalan tenaga kerja pribumi yang diharapkan oleh pemerintah Belanda justru mengecewakan tidak dapat bekerja secara maksimal difaktorkan pemberontakan pasukan Aceh terhadap kolonial Belanda (Ismail, 2004: 27). Akhirnya pemerintah Belanda melibatkan pemborong tenaga kerja dari Batavia (Jakarta) dan menawarkan pemborong kepada Letnan Cina di Aceh dengan menghabiskan dana yang dikeluarkan f203.00o (dua ratus ribu gulden). Adapun kendala pembagunan proyek masjid Baiturrahman dari segi material yang tidak memadai di Aceh, akhirnya didatangkan hampir seluruh dari luar Aceh, seperti kapur ${ }^{2}$, jenis-jenis batu ${ }^{3}$, besi jendela 4 , dan kayu kusen 5 . Contoh bangunan pertama masjid Biturrahman dengan berbentuk satu kubah sebagai berikut:

\footnotetext{
${ }^{2}$ Sejenis zat perekat yang didatangkan langsung dari pulau Pinang.

${ }^{3}$ Jenis batu didatangkan langsung dari Negeri Belanda, seperti batu pulam dan marmaer untuk tangga masjid. ${ }^{4}$ Dari Belgia.

${ }^{5}$ Didatangkan dari Moulmein (Birma)
}

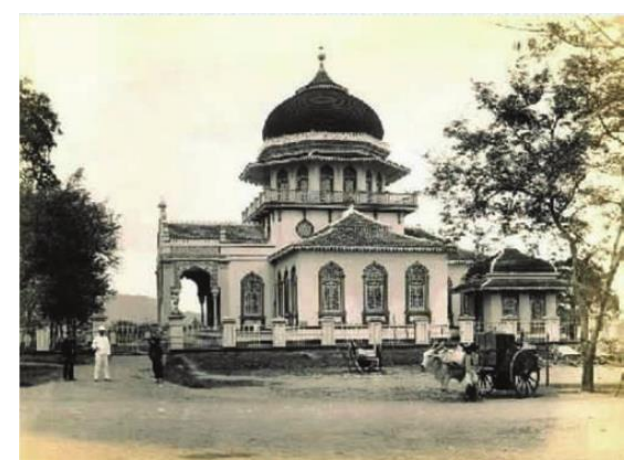

(Dokumentasi Pribadi, 2020)
Pengaruh akulturasi Bungong hias yang terdapat dalam masjid di era kolonial yang menggabungkan konsep Barat dan Timur Tengah, seperti Cardoba/Spanyol, Perancis dan Hindia Belanda (Barat). Selanjutnya masjid juga dipengaruhi budaya Timur Tengah, yaitu Arab, Turki, dan Mughal/India yang mayoritas mencakup bagian Persia. Berdasarkan uraian di atas, terlihat bahwa ada pertukaran silang budaya pada masjid Baiturrahman terkait dengan bungong hias yang sejalan dengan kearifan budaya lokal tesendiri.

Bentuk bungong hias dalam masjid Baiturrahman tidak terlepas unsur flora, arabesque, geomteris, dan alam. Sebagaimana anjuran dalam Islam Nabi Muhammad S.A.W melarang tiga jenis gambar yang sifat makhluk yang bernyawa, manusia, dan hewan. Pemahaman yang tidak dilarang dalam Islam berupa makhluk Tuhan yang tidak memiliki unsur Ruh seperti flora, alam, dan kaligrafi sebagai contoh terhadap masjid Baiturrahman. Dipertegas Leaman dalam Abu Bakar, penggunaan huruf dalam seni Islam dimaksudkan untuk mengantikan gambar makhluk yang diharamkan agama jelas keliru. Dalam seni Islam upaya menggantikan unsur berbentuk yang dilarang dalam agama, makhluk yang ditafsirkan malalui kaligarafi berbentuk gambar seekor 
burung, kijang dan ayam menggunakan ekspresi visual dengan huruf agar dapat mengantikan dengan gambar (Leman, 2005: 92).

Penempatan bungong hias ditempatkan dibidang masing-masing yaitu; mihrab, kolom pilar dalam, plafon, mimbar, ventilasi dan pintu tembaga kuningan. Bungong hias yang terapkan terdiri dari unsur flora, kaligarafi, geometris, dan alam. Bungong hias yang merupakan unsur alam seperti bungong puta taloe (bunga tali berputar), bungong meusingklet (bunga berurutan), bungong kupula (bunga yang ditanam), tangke putik bungong (tangkai putik bunga), bungong meulu (bunga melati), bungong ban keumang (bunga beru mekar), bungong ajoe-ajoe (bunga rebung mekar), bungong mahkota (bunga mahkota), oen bungong (daun bunga), bungong kelopak (kelpoka benga), bungong seulupok (bunga teratai dengan empat kelopak), bungong meucanek (bunga beruntun), bungong matauroe (bunga matahari), bungong putik (putik bunga), pucok rebong (pucuk rebung), bungong mawoe (bunga mawar), dan bungong sagoe (bunga sudut). Sedangkan unsur alam terdiri dari lampu kande (lampu lentera), awan meucanek (awan berarak), rante (rantai), dan puta taloe (putar tali) adapun dengan pola geometris dan arabesque ialah muqarnas, kaligarafi, segi lapan (segi delapan), geometris titik, segi nam (segi enam), dan geometris kaligarafi.

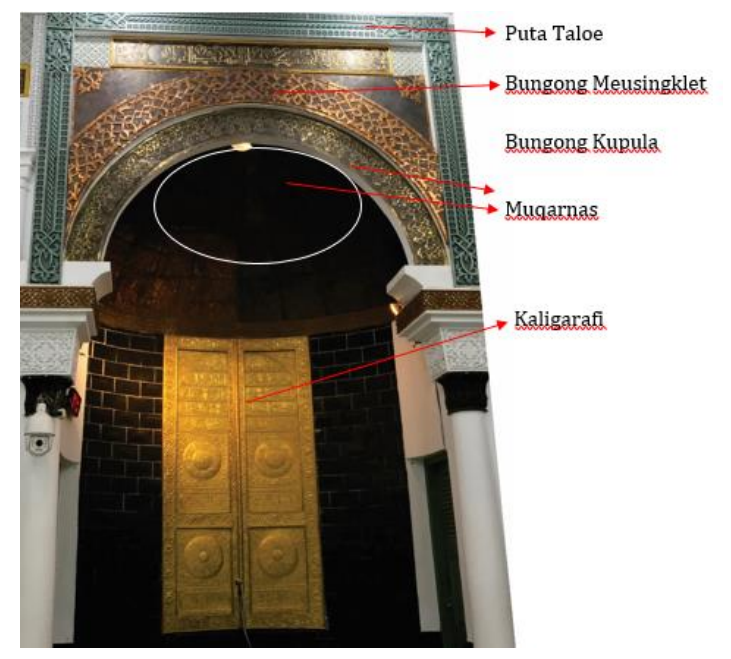

LittleJhon dalam Yusuf, menyatakan tradisi semiotik adalah bahwa benda yang dipilih bukanlah benda dalam wujud aslinya, melainkan karena semuanya membawa sesuatu yang lain pada pikiran anda sebuah hubungan, masa hidup, perjalanan, prestasi, tempat atau sejumlah pengalaman lainnya. Dengan kata lain benda-benda yang telah dipilih adalah simbol-simbol (2008: 53). Pernyataan di atas merupakan sebuah pola melihat secara komunikasi semiotik dengan tanda dan simbol, pengunaan semiotik dalam analisis penelitian menggunakan teori pierce yang terdiri dari ikon, indeks, dan symbol. Bungong hias perpaduan Barat yakni Hindia Belanda, Perancis, dan Sepanyol.

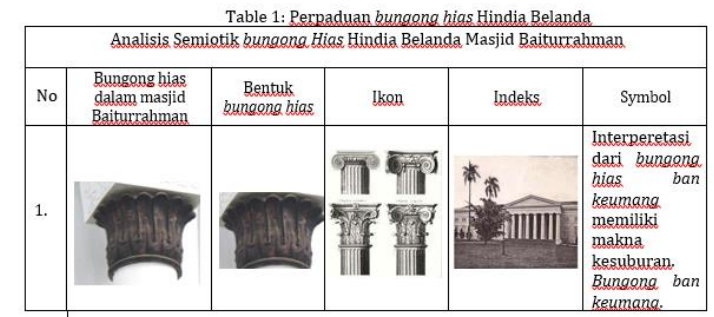

Dari objek tersebut memiliki kesamaan dari pengaruh Eropa Hidia Belanda yang berasal dari acuan Bangsa Yunani. Indeks bungong ban keumang mengartikan dari visual kenyataan bahwasanya bungong ban keumang berasal dari perwujudan konsep Hindia 
Belanda yang terdapat di kerajaan kerajaan wilyah Eropa Barat yang digunakan untuk peghias ruang Raja di dalam kastil. Terkait dengan symbol bungong hias diinterpretasikan melalui unsur peristiwa masyarakat dengan penamaan awan si oen, pengertian awan si oen berkonsep pada alam yang kemudian distimulasikan kedalam bentuk bungong hias di masjid Baitruhman. Pemaknaan dari bungong ban keumang menceritakan kehidupan sosial yang saling berkaitan dengan makhluk sosial, sama halnya dengan sifat awan yang saling membutuhkan dan memberi dari ciptaan Maha Kuasa terhadap makhluknya.

\section{DAFTAR PUSTAKA}

Asa Berger, Arthur. 1984. Signs In Contemporary Culture. Terjemahan M. Dwi Satrianto. Tiara Wancana: Yogyakarta.

Azman, Ismail. 2004. Masjid Baiturrahman dalam Lintasan Sejarah. Nadia Foundation: Medan.

Koentjaraningrat. 2009. Pengantar Ilmu Antropologi. PT Rinaka Cipta: Jakarta.

Kartika, Dharsono Sony. 2007. Kritik Seni. Rekayasa Sains: Bandung.

Pitilima, Hamid. 2011. Metode Penelitian Kualitatif. Alfebeta: Bandung.

W.Littlejhon, Stephen. Dan A.Foss, Karen. 2008. Teori Komunikasi. Terjemahan Muhammad Yusuf Hamdan. Salemba Humanika: Jakarta. 